\title{
Investigation and Study on the Ecological Environment of Dragon Lantern Colorful Paper Binding Craft in Tongliang, Chongqing
}

\author{
$\mathrm{HuiFu}^{1, \mathrm{a}}, \mathrm{CanZhou}^{2, \mathrm{~b}^{*}}$
}

\begin{abstract}
${ }^{I}$ Department of Art and Design, Chongqing vocational College Of Culture and Arts, Banan District,Chongqing,China ${ }^{2}$ Department of Architecture and Urban Planning, ChongqingVocational College of Architecture and Technology, Uni versity Town, GaoXin District, Chongqing, China

a799567636@qq.com

b*897384976@qq.com
\end{abstract}

\begin{abstract}
Tongliang District of Chongqing is regarded as the hometown of "dragon" art. From the soaring paper dragon to the exquisite dragon wood carving lying on the desk, the image of Chinese Dragon Art in this treasure land of Bashu(Chongqing and Sichuan areas) has infected countless Chinese people. "Tongliang Dragon Dance" is a comprehensive folk art form with colorful paper dragon shaped props, which integrates art, dance, music and sports. In 2006, "Tongliang Dragon Dance" was listed in the first batch of China's intangible cultural heritage list. This article makes an in-depth investigation and research on the inheritance status, inheritance dilemma and inheritance development countermeasures of Chongqing Tongliang Dragon Lantern colorful paper binding craft and explores the feasible sustainable development path of Tongliang Dragon colorful paper binding intangible cultural heritage craft, so as to provide a scientific reference for the inheritance and development of handicraft intangible cultural heritage.
\end{abstract}

Keywords: Chongqing's intangible cultural heritage, Tongliang Dragon Lantern colorful paper binding, development dilemma, development strategy, sustainable development

\section{重庆铜梁龙灯彩扎工艺生态环境调查研究}

付茾 $1, \mathrm{a}$ 洁倸 $2, \mathrm{~b}^{*}$

1 重庆文化艺术职业学院艺术设计系, 巴南区，重庆，中国

2 重庆建筑科技职业学院建筑城规学院, 大学城, 高新区, 重庆, 中国

a799567636@qq.com

b*897384976@qq.com

\section{摘要}

重庆市铜梁区，被称作 “龙” 艺术的故乡，从腾飞的扎纸巨龙到横卧在笔案的精美龙木雕，这块巴蜀宝地的 中国龙术形象感染了无数中华儿女。“铜梁龙舞” 是以彩扎龙形道具为主的集美术、舞蹈、音乐、体育竞技为 一体的综合性民间艺术形态，2006 年 “铜梁龙舞” 的道具彩扎工艺即 “铜梁扎龙” 被国家首批列入中国非物 质文化遗产名录。本文就重庆铜梁龙灯彩扎工艺的传承现状、传承困境及传承发展对策展开深入调查研究，探 索切实可行的铜梁扎龙非遗技艺可持续发展路径, 为手工艺类非物质文化遗产的传承发展提供科学的价值参 考。 
关键词: 重庆非物质文化遗产，铜梁龙灯彩扎工艺，

\section{1. 铜梁龙灯彩扎工艺传承现状}

铜梁龙彩扎工艺在形制上有蠕龙、火龙、稻草龙、 笋壳龙、黄荆龙、板登龙、正龙、小彩龙、竹梆龙、 荷花龙等十多个品种。在铜梁的扎龙艺人中, 最负盛 名的是周均安、蒋玉霖、傅全泰三位大师。在以周均 安之孙周建与周合平调查研究中发现, 周家的四个扎 龙工艺厂现阶段虽有规模, 但周家自周均安起到其孙 周合平、周建兄弟止, 目前无人学习扎龙工艺, 后代 的谋生方式的选择日益趋向多样化, 伴随老一代传承 人的逝去，相关技艺潜在走向消亡的风险。非遗文化 在民间传承, 如果没有传承人的坚持, 则这些文化遗 产就只能变成文化考古, 最终只能在博物馆看到而不 是生机勃勃的民间市井。非物质文化遗产区别于物质 文化遗产的一个基本特性, 就是依附于个体的人、群 体或特定区域空间而存在, 是一种 “活态” 文化。基 于此点, 本文就铜梁扎龙技艺生态环境及非遗传承人 的传承现状展开研究。

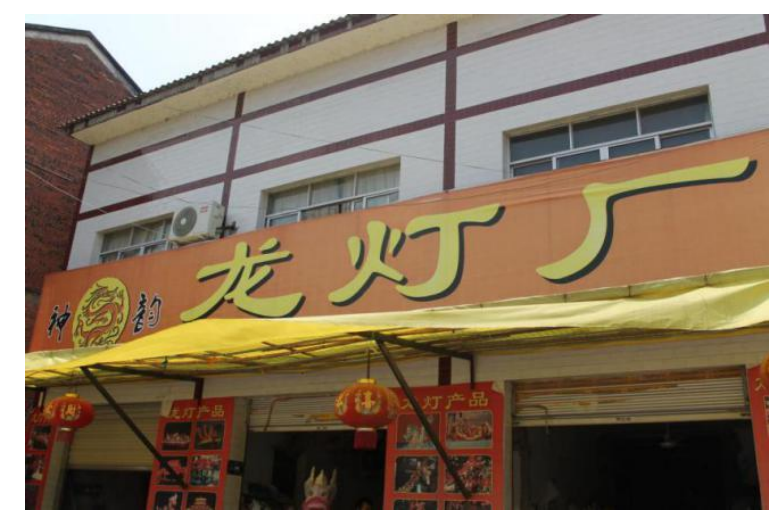

图 1 铜梁区神韵龙灯厂

\section{2. 铜梁扎龙非遗技艺发展困境}

\section{1. 企业规模效应欠佳, 各制作厂家资源共享平 台搭建不够完善}

以周建与周合平的两家店面为例, 兄弟二人的扎 龙厂各占一方, 有各自的制作技师、制作方式与买家 渠道。铜梁以龙文化傲居全国, 但在这片土地上, 各 家的龙并没有凝聚成一条巨龙, 而是栖居在各自方寸 门前。在业务承接与订单来源上, 并没有形成有效的 信息资源共享平台, 加之政府部门在向外部推广时, 对某些厂家有一定政策倾向性, 导致铜梁的扎龙产业 发展不平衡, 不能形成齐头并进的发展势头。信息资 源的不对称、数据平台的不完善、市场资源的强占争
发展困境，发展对策，可持续发展

夺, 使得铜梁扎龙不能以最优化的市场配置资源得到 最优化的发展。

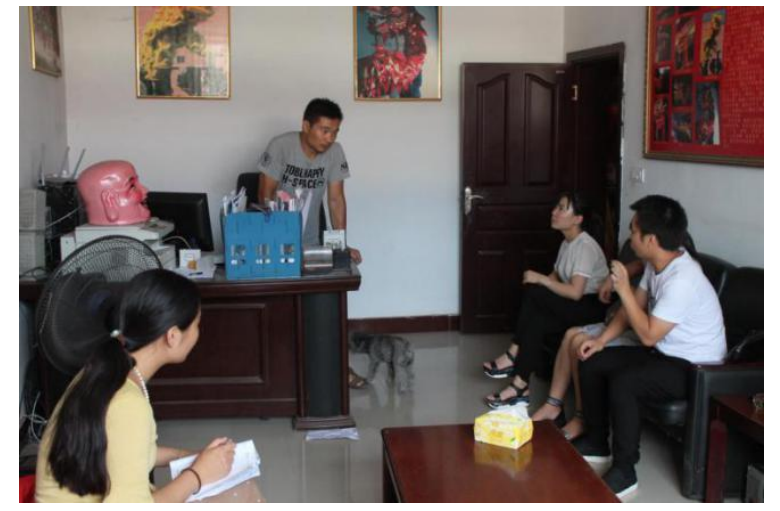

图 2 笔者同神韵龙灯厂厂长周涁探讨铜梁扎龙发展 困境

\section{2. 铜梁龙文化 IP 研发度不够、销售渠道较为 单一}

在销售渠道方面，以周健的扎龙厂为例，推广方 式仅是在引擎上网站上做线上销售, 靠点击量或是熟 人介绍来接受订单, 没有形成线上十线下成熟完善的 经营模式。承接项目多为单位、社会团体节目演出, 制作周期在十天到一个月, 季节性较强, 单个扎龙价 格不菲达几千到万元不等。在产品研发推广方面, 对 铜梁龙的文化深度与文化赋能挖掘度不够, 并没有形 成一整套的 “龙文化” 经营理念与推广模式。且政府 部门推广力度欠缺, 产品销售范围大多局限在成都、 重庆巴渝地区，“龙文化” 形象与 “龙文化” 品牌没 有很好的在全国范围内得到宣传推广。相比较广州沿 海地区的舞龙狮而言, 广州舞龙狮经过数百年的发展 积淀研发创新, 现如今已形成一整套的舞龙狮文化内 核与龙狮形象 IP, 当地企业设置专业的产品设计研 发团队, 不断更新 “舞龙狮文化” 的产品形象与衍生 品类别, 潜移默化的增强群众对舞龙狮的认知认同 度。且地方政府在公共场合等适当时机极力介绍推崇 推广龙狮文化, 将舞龙狮衍生品作视作城市文化形象 将其以文化产品的形态推送出本辖区本地域, 加至广 州地区舞龙狮产业生态环境较为完善, 产业分工明 晰, 产品制作成本较低, 单个龙狮售价仅为一千元左 右, 这又极大的刺激了市场需求, 促使龙狮产品的生 产销售在良性循环的发展轨迹上越走越远。 


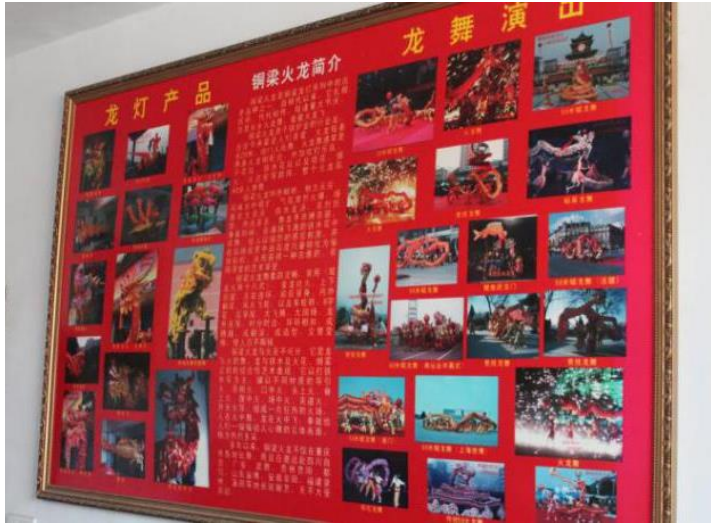

图 3 商演铜梁扎龙造型

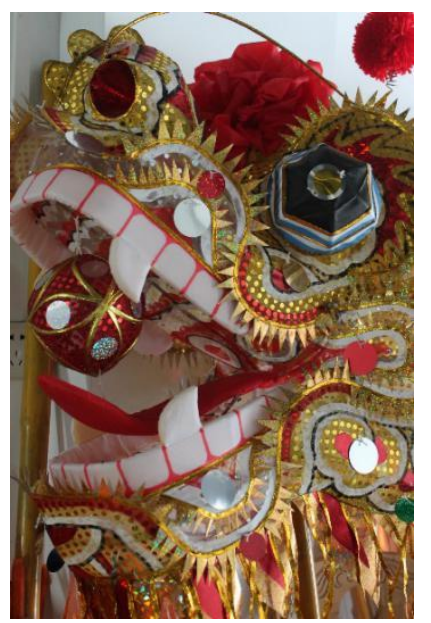

图 4 为商业演出而制作的铜梁扎龙造型

\section{3. 扎龙非遗技艺传承人老龄化趋势严重, 年轻 后备军不足}

周合平的扎龙厂的赵正师傅, 自年轻时学艺, 调 研发现，制作一条扎龙包括扎龙骨、龙身、龙头三个 部分, 基本形制完成后还需在龙骨上作彩绘, 销售淡 季时, 赵师傅需一人完成扎龙所有工序。在企业规模 上,一间扎龙厂有十几个工人, 但淡季驻守企业仅两 三人, 鲜有年轻人愿意来学, 偶有来学, 至多两三年 也就离开, 这就造成了铜梁扎龙传承青年接班人短 缺, 后继传承断层的尐施局面。扎龙是一项民间技艺 活动, 要吸引年青一代人的眼光, 就需要把其中的经 济价值与文化价值挖掘出来, 把其产能效应与社会效 应推广到年青一代中去, 让年轻人看到产业背后存在 的巨大潜力潜能。铜梁扎龙, 这门代门表中华精神的 才艺才不会在西南大地上失传。

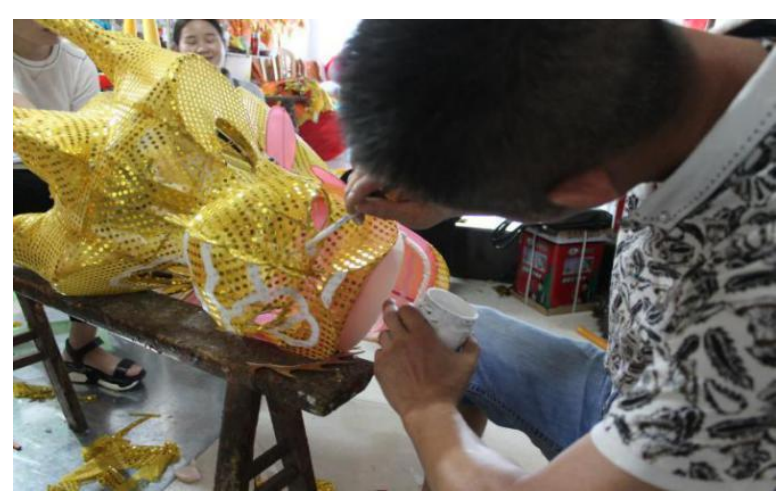

图 5 扎龙图案绘制

\section{3. 铜梁扎龙非遗技艺可持续发展对策研究}

\section{1. 与艺术院校、高校艺术类专业合作, 开发研 制高水准的龙文化企业形象 I P与文创衍生品}

铜梁扎龙企业由于受困于产业规模与设计人才 稀缺等限制性因素, 在产品研发上往往单一化、类型 化。但这一制约因素也为铜梁扎龙寻求发展新方向、 探索校企合作开辟了道路方向。重庆艺术类院校多设 有产品设计、视觉平面设计等相关设计专业, 此类专 业多开设有产品研发、文创衍生品设计、企业形象 I $\mathrm{P}$ 设计等一系列专业课程, 此类专业课程在产品的定 位、研发、甚至推广销售都有一整套完善的流程体系， 更为重要的是, 年轻大学生具有更为蓬勃的设计理 念、更为大胆的设计思路与创新意识。铜梁扎龙企业 与高校合作，于企业而言，可以寻求设计资源配置最 优化, 节流设计成本, 研发出更具创新形态的产品类 型，推广出更符合当下年轻人审美观的 “国潮龙” 非 遗产品。另一方面, 于高校而言, 开展校企合作能够 给在校大学生提供参与到真实企业项目的实践机会, 在市场的现实需求中去研发开发产品。对于扎龙企 业、高校而言, 都是具有积极意义的合作发展之路。

\section{2. 举办社会铜梁扎龙设计赛事, 持续扩大铜梁 龙社会感召力影响力}

现阶段, 铜梁扎龙的社会影响力局限于西南巴渝 一带, 举办大规模社会设计赛事, 感召更多的社会专 业设计机构、专业设计师参与到铜梁扎龙的形态形制 创新研究, 研发出具有时代气息、符合当代人现实生 活需求的文化产品, 吸引优秀的设计团队参与到这项 非物质文化技艺的传承中来，能够真正将 “龙文化” 的精神内涵散播并延展向社会。2020 年重庆非物 质文化遗产陈昌银麻花举办 “首届陈昌银 (陈麻花) 非遗文创设计大赛” , 设置丰厚奖金, 召集社会设计 师个人、设计师团、在校师生体广泛参赛, 极大的扩 大了品牌效应与社会效应。铜梁扎龙非遗技艺与陈昌 银麻花同属重庆非物质文化遗产，借鉴其举办大型社 会赛事的经验方法, 能够为铜梁扎龙非遗技艺迈出巴 渝、持续扩大社会影响提供切实可行的路线参考。 


\section{3. 政府职能部门提供政策利好, 探索铜梁扎龙 产业可持续发展}

2018 年, 铜梁区文化旅游部门和太平镇党委政府探 索出 “公司+彩扎专业合作社+农户 (包含建卡贫困 户）” 经营模式, 在坪漆村建立龙灯彩扎基地, 开展 数期龙灯彩扎工艺培训班, 由周建向村民讲解龙灯彩 扎的骨架制作、绸布裁剪、裉糊、彩绘等关键技术。 将铜梁扎龙制作后备军扩充至乡镇贫困户，对口帮 扶, 真正实现了非遗技艺项目精准帮扶脱贫。在此基 础上, 铜梁扎龙企业实现了回馈社会与培养扎龙接班 人的双重功效, 极大的扩大了社会影响力。在铜梁扎 可持续发展道路上, 政府职能部门应探索更多更有效 并切实可行的政策利好, 引导鼓励扎龙企业赋予更深 刻的社会禀赋，将这一古老灿烂的 “龙文化” 植根、 生长在市井百姓家。围绕非遗技艺传承与经济效益增 收, 政府牵头, 企业紧密配合, 共同寻求探索出符合 企业长效发展的动能机制。

\section{4. 结论}

铜梁扎龙的艺人还在辛勤的扎织、勾画一条条美 丽的龙图腾, 铜梁扎龙在其造型上的独特之处在于它 的表情是动态的、微笑的。非遗技艺传承在中国的传 承道路仍需要漫长的探索实践, 营造适宜铜梁扎龙生 长土壤, 探索出扎龙企业可持续的发展路径, 这些巨 龙才能真正走出西南, 飞跃湖泊, 越过高山, 拥抱更 多在龙文化中熏陶成长的中华儿女。

\section{REFERENCES}

[1] Zheng,X.(2008)Folk Art Research,

China Academy of Art Press, HangZhou

[2] Hong,Y.(2019)Intangible Cultural Heritage: From Inheritance to Dissemination, Tsinghua University Press,BeiJing

[3] Wang,,W.Z.(2010)Intangible Cultural Heritage Generality, Education Science Pres,BeiJing

[4] Jin,Y.F.(2010)Cultural Creative Industry Generality, Higher Education Press,BeiJing 